\title{
Irrational Beliefs as Mediator in the Relationship Between Activating Event and Stress in Malaysian Fully Residential School Teachers
}

\author{
Mastura Mahfar ${ }^{1}$, Khoo Hui Xian ${ }^{1}$, Faizah Abd. Ghani ${ }^{2}$, Azlina Kosnin ${ }^{2} \&$ Aslan Amat Senin ${ }^{3}$ \\ ${ }^{1}$ School of Human Resource Development and Psychology, Universiti Teknologi Malaysia \\ ${ }^{2}$ School of Education, Universiti Teknologi Malaysia \\ ${ }^{3}$ Azman Hashim International Business School, Universiti Teknologi Malaysia \\ Correspondence: Mastura Mahfar, School of Human Resource Development and Psychology, Universiti \\ Teknologi Malaysia. E-mail: mastura@utm.my
}

\author{
Received: July 31, $2018 \quad$ Accepted: August 25, $2018 \quad$ Online Published: September 28, 2018 \\ doi:10.5539/ass.v14n10p21 URL: https://doi.org/10.5539/ass.v14n10p21
}

\begin{abstract}
Teacher stress has been a major concern among researchers as it has negative impact on teaching profesion. This study aimed to test the mediating effect of irrational beliefs on the relationship between activating event as the independent variable and stress as the dependent variable. Data were collected from a sample of 201 teachers from seven Malaysian Fully Residential School (FRS) in the Johor state by using stratified random sampling. The Teacher Irrational Beliefs (TIB), Teacher Activating Event (TAE), and Teacher Stress (TRS) questionnaires were employed to measure irrational beliefs, activating events, and stress of teachers. The Pearson coefficient correlation was used to determine the relationships among variables and multiple regression analysis was used to verify the presence of mediation effects. In general, the correlation results showed that there were positive relationships among variables. The findings of regression analysis indicated that irrational beliefs mediate the relationship between activating event and stress among FRS teachers. This findings highlighted the teachers' irrational beliefs as the major determinants of emotional problems rather than activating event itself which comply with the ABC Model based on Rational-Emotive Behavioral Therapy (REBT) approach.
\end{abstract}

Keywords: irrational beliefs, activating event, stress, fully residential school teachers

\section{Introduction}

Teaching is the most stressful occupation compared to other occupations, such as nursing, managing, professional and community service occupations (Health and Safety Executive, 2000). The Health and Safety Executive (2000) revealed that two out of five teachers in the United Kingdom suffered from stress, compared to one in five workers from other occupations. Teachers' work stress are related with unpleasant emotions that leads to several negative effects, including dysfunctional behaviors in relations to pupils, colleagues and parents (Bora et al., 2013), job burnout (McCarthy et al., 2009), decreased teaching efficacy and job satisfaction (Klassen, 2010), and teachers' commitments (Klassen \& Chiu, 2011). Thus, teachers' risk of experienced burnout and stress are steadily increasing and therefore, the measuring of teacher stress is crucial in understanding the process that lead to teacher stress (Azlihanis et al., 2009).

In Malaysian studies, previous research showed that teachers with high level of stress faced many stressors at working environment (Jayakaran \& Koroush, 2010; Nurul Izzah et al., 2010). Jayakaran and Koroush (2010) had found teachers' burnout level which closely related to stress were different with regard to different age group and workload categories among primary and secondary school teachers in Malaysia. Other than that, up to 34 percent of stress prevalence, 17.4 percent of mild-stress suffered by secondary school teachers, and indicated non-job-related factors such as age, duration of work and psychological job demands were significantly associated with stress level of teachers (Azlihanis et al., 2009).

According to Rational Emotive Behavior Theory which was previously known as Rational Emotive Therapy (RET) and was developed by Albert Ellis in the 1950's, "stress" or people's reactions including emotional and behavioral disturbances are not determined by the activating events, but by their beliefs about the activating event itself (Ellis et al., 1997). In other words, individuals experience depression, stress, anxiety, and other emotional disturbances are result from incorrect reasoning and irrational beliefs (Ellis, 1991; Ellis \& Bernard, 
2006).

Therefore, activating event was also considered as stressor and stress factors that may lead to stress among teachers. Hence, some research had studied and assessed about stress and its risk factors among teachers. A study conducted by Nurul Izzah et al. (2010) revealed that teacher stress was mainly due to student's misbehaviour. Besides that, Nurul Izzah et al. (2010) also identified mental well-being of teacher was influenced by workload and gender which comply with findings of Jayakaran and Koroush (2010).

The 'ABC' Model is at the heart of the REBT theory of psychological disturbance which can help individuals to understand the causes of stress (Ellis, 1991; Dryden \& Branch, 2008). According to ABC Model, activating event (A) such as stressor or stress factor is not the ultimate reason led to stress among teachers (see Figure 1). This situation had also lead to misconception of stress which was represented by $\mathrm{C}$ (Counsequences). These consequences can be negative emotional, behavioural, and thinking in nature. "Stress" was determined by how individual perceived and evaluated negative activating events, not determined by actual event happened in daily lives (Ellis et al., 1997). In other words, stress is largely determined by cognitive factors or beliefs held by individuals (Dryden, 2012). Beliefs can be irrational or rational. Rational beliefs are associated with any flexible, logical and non-extreme views (Dryden \& Branch, 2008). For example, "I would like to be successful, but if I'm not, I'm still a worthwhile person". On the contrary, irrational beliefs are always related to rigid, illogical and non-extreme views (Dryden \& Branch, 2008).

Besides that, individual with irrational beliefs (B) is also believed to experience unhealthy beliefs towards negative event (A) compared to individual with rational beliefs. Individuals with high levels of irrational beliefs develop unhealthy negative emotional responses in the presence of negative activating events (Ellis, 2002). Thus, stress experienced by individuals has a significant relationship with their beliefs system toward events (Ellis, 2002).

In educational setting, teachers' mental health also has a great influence on their teaching performance in the classoom (Bora et al., 2013). Although teachers play an important part of their students' spiritual and emotional lives due to their close relationship with students, however, many cases showed that teachers are more likely to use irrational thinking in the process of communicating with their students (Tanhan \& Şenturk, 2011). The issue of teachers' stress need to be taken into consideration because stress may affect their job satisfaction, teachers' efficiency in schooling activities, their interactions to students and colleagues, and even their own families' wellness (Bora et al., 2013). In addition, David and Szamoskozi (2011) suggest that future studies should further explore the relationships between irrationality and stress in organizational setting.

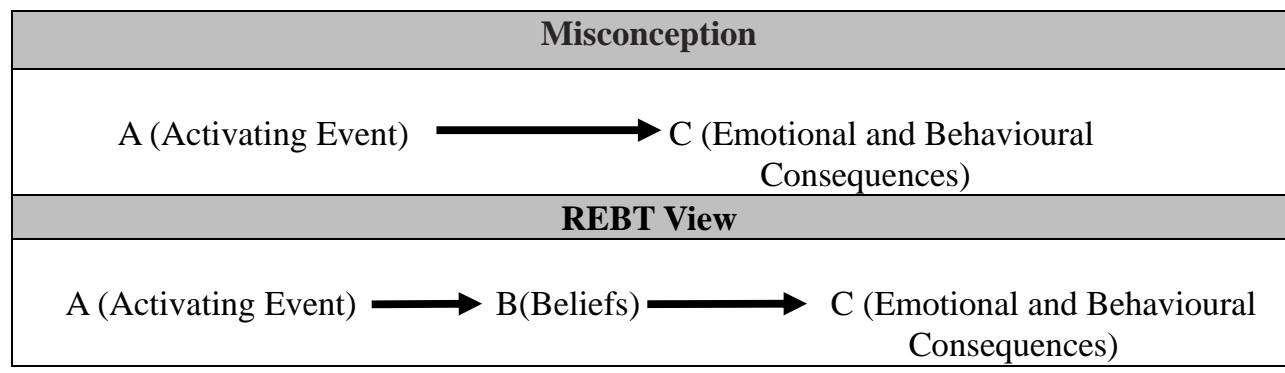

Figure 1. ABC Model based on REBT approach

(Source: Ellis \& Bernard, 1983)

Therefore, the objective of the study was to identify the relationships among variables which are between activating event and stress, activating event and irrational beliefs, and between irrational beliefs and stress among FRS teachers in Johor state. As there is possibility of indirect causes of stress, the influence of any mediator in the relationship between activating event and stress among teachers need to be studied. According to REBT approach, beliefs (B) mediate the impact of activating events (A) on emotional and behavioral disturbances (C) (Ellis, 1991; Dryden \& Branch, 2008). Thus, this study was also carried out to test the mediating effects of irrational beliefs on the relationship between activating event and stress among Malaysian FRS teachers in Johor state.

\section{Literature Review}

The discussion of literature review is about the three main variables to be examined in this study which are 
activating events, irrational beliefs and stress among teachers.

\subsection{Activating Events}

Activating event (A) refers to any inference that individual has made about the situation or some aspect of the situation (Dryden, 2006). Activating event can be actual events or inferences which may be correct or incorrect. Moreover, activating event can be external events or internal events and can stand for past, present or future events. However, the event is not a direct cause to the positive or negative feelings of an individual (Koffler, 2005).

\subsection{Irrational Beliefs}

In REBT, any rigid, illogical and extreme ideas or views are known as irrational beliefs (Dryden \& Branch, 2008). The irrational beliefs produce inappropriate emotional and behavioral disturbances (Ellis, 2002; Tanhan, 2014). There are four categories of irrational beliefs, namely demandingness (e.g., "My colleagues must always respect me"), awfulizing/catastrophizing (e.g., "It is awful if my colleagues do not respect me"), low frustration tolerance (e.g. "I cannot stand if colleagues do not respect me"), and global evaluation (e.g., "My colleagues are bad if they do not respect me") (DiLorenzo et al., 2007; David et al., 2005; Ellis \& Dryden, 1997; Walen et al., 1992). The demandingness is viewed as a core belief in which a person has absolutistic ideas that expressed in the form of "should," "ought" and "musts" either towards self, others or life condition (Ellis, 1991; David et al, 2005; DiLorenzo et al., 2007).

\subsection{Stress}

Stress is represented by consequences (C) of holding beliefs about critical or negative event based on REBT approach (Dryden \& Branch, 2008). Stress is defined as a condition where the mental and physical of individuals need to be arranged or adapted according to the environment (Coon \& Mitterer, 2007). Besides that, stress is an adaptive response that is experienced by the individual differences due to an action, situation or event that place a specific demand on the person (Gibson et al., 2003). However, Amat Taap et al. (2003) asserted that stress at the workplace can occur when employees feel "under loaded" through lack of stimulus and social contact.

\subsection{Hypotheses Development}

\subsubsection{Relationship Between Activating Event and Stress}

Shernoff et al. (2011) had carried out a qualitative study among 14 urban teachers in Midwestern city, USA. The findings of their study showed that there are several sources of stress which are physical health, personal relationship, work performance, and emotional well-being. The identified impacts of occupational stress are all negative towards job performance, relationship with students, job satisfaction, career engagement, and attendance.

Other than that, Kyriacou (2001) identified a number of sources of teachers stress in his study. These include demotivated and unruly students in class; time pressure and heavy load of curricular and extracurricular duties; ever-changing educational system; problems with colleagues and school administration; low self-esteem; role conflict and ambiguity, and unconducive working conditions. These sources can be considered negative activating events experienced by the teachers. However, these sources of stress are distinct for each teacher individually. Therefore, the hypothesis was developed as follow:

$\mathbf{H}_{1}$ : Activating event (A) is significantly related to stress (C) among FRS teachers.

\subsubsection{Relationship Between Activating Event and Irrational Beliefs}

The relationship between activating event and irrational beliefs was further supported by David et al. (2005) who conducted a study on empirical investigation of Albert Ellis's Binary Model of Distress among U.S. and Romanian context breast-cancer patient. The findings of their study showed that the patient who facing stressful situation such as upcoming breast surgery had experienced high level of irrational beliefs with both functional and dysfunctional negative feelings.

Tanhan (2014) in his study revealed that irrational beliefs were found to be significantly influenced by factors such as satisfaction with the teaching profession, seniority, depression, and industry variables among voluntarily-participating teachers working in Van. Therefore, this study suggests that:

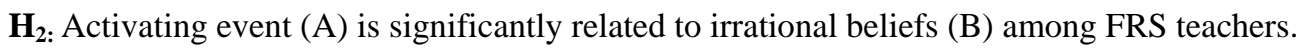

\subsubsection{Relationship Between Irrational Beliefs (B) and Stress (C)}

The presence of irrational beliefs in relation to distress has been strongly supported by research data. For example, Stebbins and Pakenham (2001) in their study found that irrational beliefs were related to higher levels 
of psychological distress in caregivers of persons with traumatic brain injury. Meanwhile, a study by Laura and María (2006) had also found the relationship between the four types of irrational beliefs and distress among secondary school teachers in Madrid region. Furthermore, teachers with lower levels of irrational beliefs were perceived more effective than teachers who reported higher levels of irrational beliefs (Endes, 1996).

Meehan (2011) also discovered the relationship between irrational beliefs and stress among teachers in which teachers possessing high level of irrational beliefs may view themselves as having high level of stress. Moreover, local research done by Mastura et al. (2012) proved positive relationships between the four subscales of irrational beliefs (demandingness, awfulizing, low frustration tolerance, and global evaluation) and stress among FRS respondents in Johor state. Thus, the hypothesis was developed as follow:

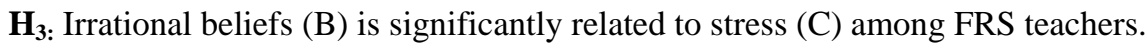

2.4.4 Mediation Effects of Irrational Beliefs (B) on the Relationship Between Activating Event (A) and Stress (C)

There are some early scientific evidence for this relation from Western perspective, for example, a study by Jacofsky (2005). However, the irrational beliefs have been far less investigated as mediator in the relationship between activating event and stress, especially in the fully residential school context. Jacofsky (2005) proved that irrational beliefs as partial mediator in the relationship between activating event and stress among psychology graduate students. In fact, Bora et al. (2013) have studied teachers' irrational beliefs as mediator, however, the independent variable in their study was different from the current study which is REBT intervention (independent variable) and the dependent variable is teachers' behaviors and emotions.

In addition, there are many previous studies carried out on the relationship between activating event (stressor) and stress, activating event and irrational beliefs, and the relationship between irrational beliefs and stress. However, further research still needs to clarify the nature of functional and dysfunctional emotions and the role of rational and irrational beliefs (Mogoase et al., 2013).

Ellis (1991) asserted that different stress situation has significant relationship with individual's perception and cognitive towards that particular situation. Thus, stressor, irrational beliefs and teacher stress can be put into discussion in the context of $\mathrm{ABC}$ Model. This can be done by discussing stressor in the context of activating event (A), irrational belief in the context of beliefs (B), and stress in the context of consequences (C) to avoid general assumption of stress is determined by the activating event. Thus, this study suggests that:

$\mathbf{H}_{4:}$ Irrational beliefs (B) mediate the relationship between activating event (A) and stress (C) among FRS. teachers.

\section{Method}

\subsection{Participants and Sampling Procedures}

The participants in this study were 201 FRS teachers in Johor state. According to data from Education Management Information System (EMIS), the population of FRS teachers from all seven fully residential schools in Johor state, Malaysia is 420. The sample size was determined through Krejcie and Morgan's (1970) table. Based on the table, a sample size of 201 FRS teachers was taken as the representative sample of the target population.

Then the stratified random sampling method was applied for selecting the sample of this study. Stratified random sampling is particularly useful because the subsets of each stratum are taken in proportion to the size of each strata (Sekaran \& Bougie, 2010). In this study, the population was randomly stratified based on seven fully residential schools. Each subgroup in the sample must contain enough individuals to adequately represent its segment of the population. The questionnaires were distributed to the respondents by using a random number table to ensure that everyone has probability to be chosen as a respondent.

\subsection{Measures}

Teacher Irrational Beliefs (TIB) (Mastura, 2015) was used to evaluate irrational beliefs of FRS teachers. The TIB was developed by taking into account fully residential school teachers' cultural norms and background contexts. The scale contained 49 items to measure FRS teacher's irrational beliefs based on four dimensions, namely demandingness, awfulizing, low frustration tolerance and global evaluation which were derived from REBT approach. Reliability analysis of TIB was done by using Rasch analysis which showed high item reliability $(\alpha=.95)$ and acceptable person reliability $(\alpha=.78)$.

Teacher Activating Event (TAE) (Mastura, 2015) was used to measure teachers' activating events. The TAE scale consists of 34 items to measure FRS teachers' activating events that frequently encountered by FRS teachers 
such as workload, student's attitude, administration's attitude, and teacher's (colleague) attitude. Reliability analysis of the TAE showed acceptable item reliability $(\alpha=.74)$ and high person reliability $(\alpha=.92)$.

Teacher Stress (TRS) (Mastura, 2015) is a 34-item that measures teachers stress. The TRS asked respondents to rate each item which related to stress that frequently encountered such as workload, student's attitude, administration's attitude, and teacher's (colleague) attitude. Reliability analysis of the TAE also showed acceptable item reliability $(\alpha=.81)$ and high person reliability $(\alpha=.96)$ for stress.

The three questionnaires also showed that the principal component analysis (PCA) returned an observed value of more than $40 \%$ variance, explained by measures which indicated that the TIB, TAE, and TRS measured the stipulated variables. A 5-point Likert-type scale was employed to present the score of irrational beliefs, activating event and stress indicated among each respondent. Furthermore, a questionnaire was drawn up to collect basic demographic information of respondents.

\section{Results}

\subsection{Initial Data Analysis}

The data was first analyzed using descriptive statistic to give an overview regarding the distribution of data. A total of 201 FRS teachers participated in the study. Male teachers consist of $32.8 \%(n=66)$ of the sample and female teachers $67.2 \%(n=135)$. The major portion of the respondents $(34.8 \%)$ was aged between 21 to 30 years old, followed by the respondents aged between 31 to 40 years old. Besides that, there were $24.4 \%$ of respondent who aged between 41 to 50 years old and the minority of respondents was who aged between 51 to 60 years old with population of $4.0 \%$. On the other hand, there were $7.9 \%$ of respondents was neither above 21 years old nor below 60 years old. 190 (94.5\%) teachers were Malay, 141 were married (70\%), 191 (95\%) had a degree and 122 have teaching experience less than 10 years.

Table 1 presents the descriptive statistics which computed for all data prior to the stage of conducting the detailed statistical analyses. The results showed that the irrational beliefs mean is 155.95 ( $\mathrm{SD}=9.47$ ), the activating event mean is 127.20 ( $\mathrm{SD}=14.35)$, and the stress mean is 120.00 ( $\mathrm{SD}=19.58)$.

The Pearson coefficient correlation is used to explain the relationships among variables. The results showed that the three hypotheses $\left(\mathrm{H}_{1}, \mathrm{H}_{2}\right.$, and $\left.\mathrm{H}_{3}\right)$ have been supported in this study. The results indicate that activating event $(r=0.67, p<.05)$ has a significant relationship with stress, and irrational beliefs $(r=0.15, p<.05)$. Irrational beliefs have been shown to have a significant relationship with stress $(r=0.21, p<.05)$.

Table 1. Descriptive Statistics and Coefficient Correlations

\begin{tabular}{cccccc}
\hline & Mean & Std. Deviation & I & II & III \\
\hline Activating event (A) & 127.20 & 14.35 & 1 & & \\
Irrational beliefs (B) & 155.93 & 9.47 & $0.15^{*}$ & 1 & \\
Stress (C) & 120.00 & 19.58 & $0.67^{*}$ & $0.21^{*}$ & 1 \\
\hline
\end{tabular}

* Correlation is significant at the .05 level

$\mathrm{I}=$ Activating event, II = Irrational beliefs, III = Stress

\subsection{Multiple Regression Analysis}

The scores of TIB, TAE and TRS were used to describe the normality distribution of the data. The values of skewness and kurtosis for all variables in items were indicated with normal distribution before proceeding hierarchical multiple regression, normality of the data was confirmed. The associations between scores of activating event (A), irrational beliefs (B) and stress (C) was analyzed using hierarchical multiple regression.

The detailed result of the mediation analysis using hierarchical multiple regressions with the aim of identify the mediation effect of irrational beliefs (B) were illustrated in Table 2. The result highlights that irrational beliefs (B) significantly mediated on the relationship between activating event (A) and stress (C) not completely but mediated partially. The simple linear regression in Step 1 to Step 3 had shown significant effect of each variable onto each other. The results of simple linear regression in Step 1 to Step 3 revealed activating event (A) as significant estimator to stress (C) $(\beta=.67)$, activating event (A) as significant estimator to irrational beliefs (B) $(\beta=.145)$ and also irrational beliefs (B) as significant estimator to stress $(\mathrm{C})(\beta=.212)$ at significant level of $p<.05$.

Lastly in Step 4 of mediation analysis, irrational beliefs (B) was found to partially mediate on the relationship 
between activating event (A) and stress (C) since the regression after insertion of irrational beliefs (B) was not zero and significant $(\beta=.653)$ at level of $p<.05$. As can be seen, the first block of regression explained $44.9 \%$ of the total variance of irrational beliefs $[\mathrm{F}(1,199)=162.172, p<.05]$. Addition of the remaining variables to the model (Block 2) decreased the percentage of explained stress by only $1.3 \%(0.013)$. However, this decrement was statistically significant $[\mathrm{F}(1,199)=85.137, p<.05]$, thus partially supporting the hypothesis, $\mathrm{H}_{4}$.

Next, the mediation of irrational beliefs was treated with Sobel test to analyze the effect of mediator in a more specific manner. The Sobel test is about testing how large is value of product of coefficient. The product of coefficient is the amount of variance in stress (C) that is accounted by the activating event (A) through the mechanism of mediator, and also considered as the indirect impact. If product of coefficient or $\left(c-c^{\prime}\right)$ is sufficiently large, then Sobel's test is significant and significant mediation has occurred. The result of Sobel Test had revealed statistic value $(Z=1.337, p<.05)$. This means, irrational beliefs partially mediated the relationship between activating events and stress.

Table 2. Mediation Analysis: Hierarchical Multiple Regression.

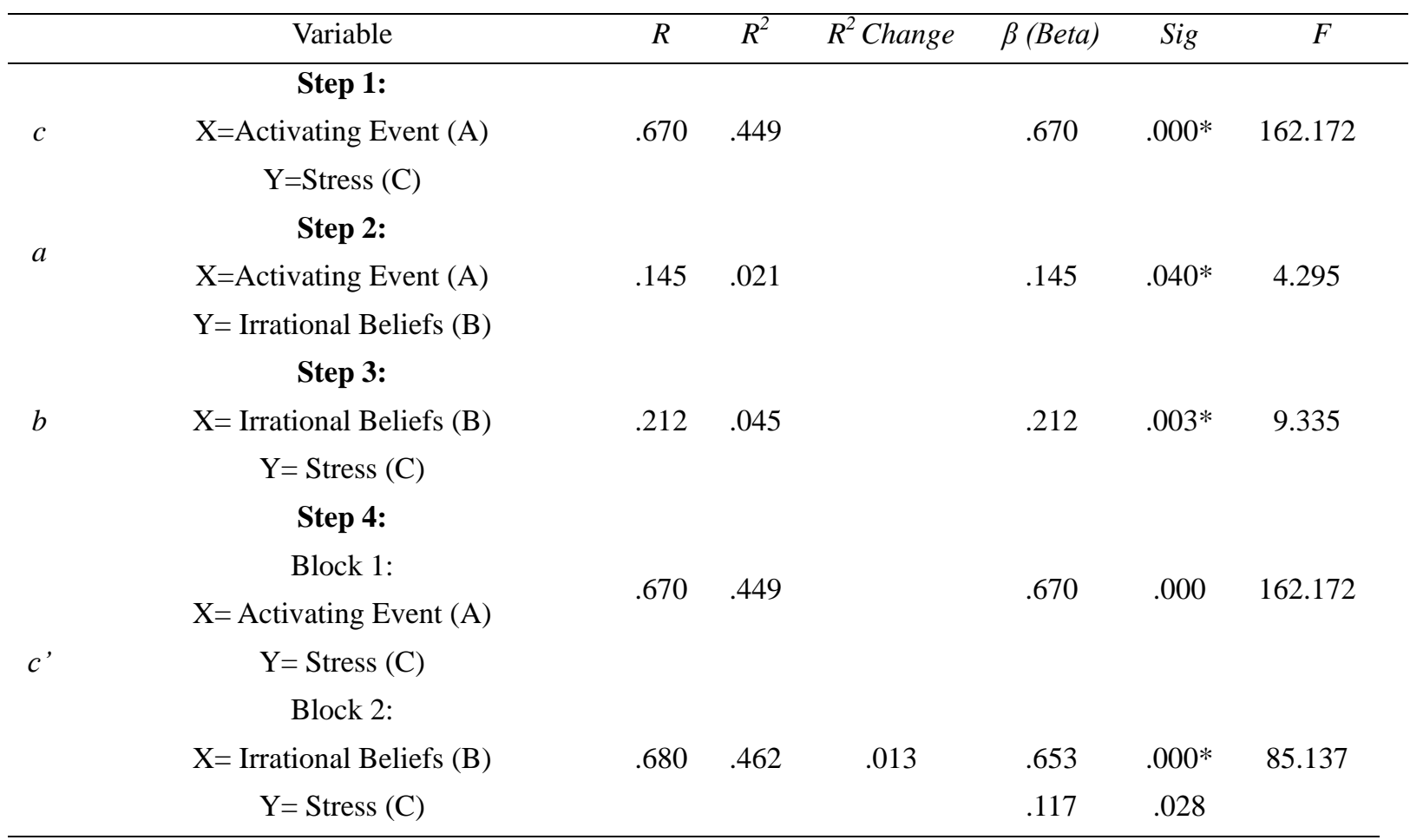

Note: $* p<.05 ; \mathrm{N}=201$

\section{Discussion}

The main aim of this study is to test the assumption of irrational beliefs (B) as mediator in the relationship between activating event (A) and stress (C) among FRS teachers. The findings of this study revealed that activating event (A) has significantly related to stress (C) among FRS teachers This finding was consistently reported in previous studies (Kyriacou, 2001; Azlihanis et al., 2009; Shernoff et al., 2011) which indicated some stressors (activating events) were significantly associated with stress among teachers. Meanwhile, this finding was also consistent with the findings of studies by Ohue et al. (2010) where stressors that affecting burnout among staff nurses were conflict with colleagues, conflict with patient, role conflict, quantitative workload and qualitative workload. This study found that teaching can be a stressful job due to high expectations from parents and students as well as pressures from colleagues and superiors. This made worse by high workload, ever changing policies and lack of appreciation for achievements (Klassen et al., 2010).

Similarly, it was also shown that activating event (A) has significantly related to irrational beliefs (B) among FRS teachers. In other words, an activating event (A) experienced by FRS teachers is regarded as a key event in triggering their irrational beliefs (B). This study was consistent with the findings of previous research (David et al., 2005) which showed that low levels of irrational beliefs were associated with low level of dysfunctional negative feelings and high level of functional negative feelings in a stressful situation. 
Other than that, the results also showed that irrational beliefs (B) has significantly related to stress (C) among FRS teachers. This finding is similar to the findings of previous research (Laura \& Maria, 2006; Lucica, 2012) which found the strong correlations between high level of distress and high irrationality among teachers. In addition, this finding was also consistent with the basic tenet of REBT where unhealthy emotions and psychological disturbances are largely due to irrationality (Ellis, 1997; Dryden, 2012). Teachers who possessed high irrational thoughts may view themselves as having less social support, more role ambiguity, and higher level of stress (Meehan, 2011). Irrational beliefs are one of the factors that could sustain the distress and, as a result, it may lead to emotional disorders (David et al., 2008). In fact, posttraumatic stress responses are also considered to be affected by irrational beliefs (Hyland et al., 2015).

Interestingly, the findings of this study have revealed that irrational beliefs (B) acts as partial mediator in the relationship between activating event (A) and stress (C). The finding of irrational beliefs as partial mediator was consistently reported in the finding of previous study by Jacofsky (2005) which showed irrational beliefs partially mediate the relationships between stress exposure and stress severity among psychology undergraduate students. This finding of study suggests that the relationship between activating events (stressors) and teacher stress is not direct, but rather it is mediated by another variable which is teachers' irrational beliefs. In other words, stressors or negative activating events as an antecedent of irrational beliefs, and this in turn will lead to emotional disturbances of FRS teachers.

This is theoretically relevant as it shows the importance of irrational beliefs as the major determinants of emotional problems rather than activating event itself which confirmed the ABC Model in the REBT approach. The key aspect of ABC Model in the REBT which explains the sequence of emotional disturbances can be used to assist individuals understand that their emotional disturbances result from their evaluations and beliefs they have toward negative life events rather than by the events per se (Ellis et al., 1997; Davies, 2006).

According to David et al. (2010), irrational beliefs can lead to dysfunctional emotions and maladaptive behaviours. On the contrary, teachers who have the ability to think rationally and make rational decisions are integral to achieving the goals desired from education (Tanhan, 2014). The significant way of reducing dysfunctional emotions and behaviors is through the modification of people's irrational thoughts (Ellis, 1991; Dryden \& Branch, 2008). Therefore, school counselors who offering assistance to teachers should take into consideration teachers' irrational beliefs, so that they can modified their dysfunctional emotions and maladaptive behaviors efficiently (Bora et al., 2009). Many previous studies have proved that the Rational-emotive behavior therapy (REBT) can also be applied in the educational field and in organizations (Bora et al., 2009; David \& Szamoskozi, 2011; Ugwoke et al., 2018).

Other than that, the application of ABC Model has also been proved to be suitable for Malaysian FRS teachers. Figure 2 presents the summary of research outcome for this research in which irrational belief was proved as significant mediator in the relationship between activating event (A) and stress (C) among FRS teachers.

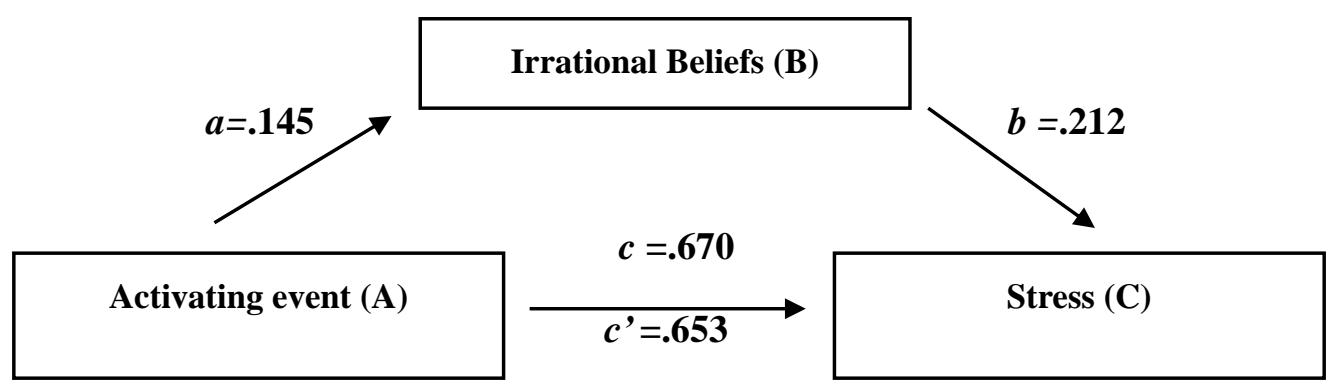

Figure 2. Summary of research outcome

However, we also acknowledged some limitations of the present study and the need for further research. This study is cross-sectional and therefore, it cannot be concluded the direction of causality in this research, for example, posssesing irrational beliefs affects the teachers stress. To investigate the direction of causality, an experimental design can be used to gain more details about the findings of study. Another limitation is the study is limited to a small sample of fully residential school teachers in Johor state. Thus, the results may not be representative of the secondary school or private funded schools in Malaysia. Hence, future studies could use a diverse and larger sample, for example teachers from other states or other levels in order to gain better understanding of the study among teachers in Malaysia. Finally, future studies could explore in more detail by focusing on each dimension of irrational beliefs (demandingness, awfulizing, low frustation tolerance and global 
evaluation) to identify their mediator effects in the relationship between activating event (A) and stress (C) as they could prove significant from a theoretical aspect.

\section{Conclusion}

The aim of the present study is to extend the existing literature using ABC Model based on REBT approach to test whether the irrational beliefs (B) act as mediator in the relationship between activating event (A) and stress (C) among FRS teachers. In conclusion, this study reveals that irrational beliefs (B) mediate the relationship between activating event (A) and stress (C) among FRS teachers. The result obtained from the regression model complies with the ABC Model based on Rational-Emotive Behavioral Therapy (REBT) approach. These findings suggest the importance of the irrational beliefs and its impact on teachers stress rather than activating event itself. The REBT approach is also viewed as a cognitive orientation which are comprehensive, and psychoeducational in order to help individuals manage their emotional and behavioral disturbances by thinking rationally (Bernard \& Joyce, 1984; Ellis \& Bernard, 2006). Considering the evidence from previous research and the present study, these findings should be given due attention in promoting rational beliefs in order to reduce the FRS teachers' stress.

\section{Acknowledgments}

The authors would like to thank the Universiti Teknologi Malaysia for funding of this research project under Research University Grant (RUG) and also all participants for taking part in the study.

\section{References}

Bernard, M. E., \& Joyce, M. R. (1984). Rational-emotive therapy with children and adolescents: Theory, treatment strategies, preventative methods. New York: A Wiley-Interscience Publication.

Bora, C. H., Vernon, A., \& Trip, S. (2013). Effectiveness of a rational emotive behavior education program in reducing teachers' emotional distress. Journal of Cognitive and Behavioral Psychotherapies, 13(2), 585-604.

Bora, C., Bernard, M. E., Trip, S., Decsei-Radu, A., \& Chereji, S. (2009). Teacher irrational belief scale-preliminary norms for Romanian population. Journal of Cognitive and Behavioral Psychotherapies, 9(2), 211-220.

Coon, D., \& Mitterer, J. O. (2007). Introduction to psychology: Gateaways to mind and behavior. Belmont: Thomson Wadsworth.

David, A. R., \& Szamoskozi, S. (2011). A meta-analytical study on the effects of cognitive behavioral techniques for reducing distress in organization. Journal of Cognitive and Behavioral Psychotherapies, 11(2), 221-236.

David, D., Lynn, S. J., \& Ellis, A. (Eds.). (2010). Rational and irrational beliefs: Research, theory, and clinical practice. New York: Oxford University Press.

David, D., Montgomery, G. H., Macavie, B., \& Bovbjerg, D. H. (2005). An empirical investigation of Albert Ellis's Binary model of distress. Journal of Clinical Psychology, 61(4), 499-516. https://doi.org/10.1002/jclp.20058

David, D., Szentagotai, A., Lupu, V., \& Cosman, D. (2008). Rational emotive behavior therapy, cognitive therapy, and medication in the treatment of major depressive disorder: A randomized clinical trial, posttreatment outcomes, and six-month follow-up. Journal of Clinical Psychology, 64, 728-746. https://doi.org/10.1002/jclp.20487

Davies, M. F. (2006). Irrational beliefs and unconditional self-acceptance. I. Correlational evidence linking two key features of REBT. Journal of Rational-Emotive and Cognitive-Behavior Therapy, 24(2), 113-124. https://doi.org/10.1007/s10942-006-0027-0

DiLorenzo, T. A., David, D., \& Montgomery, G. H. (2007). The interrelations between irrational cognitive processes and distress in stressful academic settings. Personality and Individual Differences, 42, 765-776. https://doi.org/10.1016/j.paid.2006.08.022

Dryden, W. (2006). Getting started with REBT: A concise guide for client. New York: Routledge.

Dryden, W. (2012). The "ABCs" of REBT III: A study of errors and confusions made by Ellis and Joffe Ellis 2011. Journal of Rational Emotional Cognitive Behavior Therapy, 30, 188-201. https://doi.org/10.1007/s10942-011-0140-6

Dryden, W., \& Branch, R. (2008). The fundamentals of rational emotive behaviour therapy (2nd ed.). New 
Jersey, USA: John Wiley \& Sons, Ltd.

Ellis, A. (1991). Reason and emotion in psychotherapy (Revised and updated). New York: Carol Publishing Group.

Ellis, A. (2002). Overcoming resistance: A rational emotive behavior therapy integrative approach (2nd ed.). New York: Springer Publishing Company.

Ellis, A., \& Bernard, M. E. (1983). Rational-emotive approaches to the problems of childhood. New York: Plenum Press.

Ellis, A., \& Bernard, M. E. (2006). Rational emotive behavioral approaches to childhood disorders: Theory, practice and research. New York: Springer, Inc.

Ellis, A., \& Dryden, W. (1997). The practice of rational emotive therapy. New York, NY: Springer Publishing Company.

Ellis, A., Gordon, J., Neenan, M., \& Palmer, S. (1997). Stress counseling: A rational emotive behavior approach. New York: Springer Publishing Company.

Endes, R. B. (1996). The role of irrational beliefs in behavioral consultation: Implications for treatment outcomes. Dissertation Abstracts International-Section A: Humanities and Social Sciences, 56 (8-A), 3055.

Gibson, J. L., Donnelly, J. H., Ivancevich, J. M., \& Konopaske, R. (2003). Organizations: Behavior structure processes. New York: McGraw-Hill.

Hadi, A. A., Niang, N. N., Daud, A., Nordin, R., \& Sulong, M. R. (2009). Prevalence and factors associated with stress among secondary school teachers in Kota Bharu, Kelantan, Malaysia. Southeast Asian Trop Med Public Health, 40(6), 1359-1370.

Health and Safety Executive. (2000). Stress at work: Who is affected most? Press release E 246:00.

Hyland, P., Shevlin, M., Adamson, G., \& Boduszek, D. (2015). Irrational beliefs in posttraumatic stress responses: A rational emotive behavior therapy approach. Journal of Loss and Trauma, 20(2), 171-188. https://doi.org/10.1080/15325024.2013.839772

Jacofsky, M. D. (2005). Mediating and moderating effects of irrationality on stress in school psychology students. Unpublished Doctoral Dissertation. St. John's University.

Jayakaran, M., \& Koroush, K. (2010). Burnout among English language teachers in Malaysia. Contemporary Issues in Education Research, 3(1), 71-76. https://doi.org/10.19030/cier.v3i1.163

Klassen, R. M. (2010). Teacher stress: The mediating role of collective efficacy beliefs. Journal of Educational Research, 103, 342-350. https://doi.org/10.1080/00220670903383069

Klassen, R. M., \& Chiu, M. M. (2011). The occupational commitment and intention to quit of practicing and preservice teachers: Influence of self-efficacy, job stress, and teaching context. Contemporary Educational Psychology, 36, 114-129. https://doi.org/10.1016/j.cedpsych.2011.01.002

Klassen, R. M., Usher, E. L., \& Bong, M. (2010). Teachers' collective efficacy, job satisfaction, and job stress in cross-cultural context. Journal of Experimental Education, 78, 464-486. https://doi.org/10.1080/00220970903292975

Koffler, A. M. (2005). Perceptions of beliefs in rational emotive therapy among college students: A multidimensional scaling analysis. Unpublished Doctoral dissertation. Hofstra University

Krejcie, R. V., \& Morgan, D. W. (1970). Determining sample size for research activities. Educational and Psychological Measurement, 30(3), 607-610.

Kyriacou, C. (2001). Teacher stress: Directions for future research. Educational Review, 53(1), 27-35. https://doi.org/10.1080/00131910120033628

Laura, B. T., \& María, P. U. (2006). Teachers' irrational beliefs and their relationship to distress in the profession. Psychology in Spain, 10(1), 88-96.

Lucica, E. C. (2012). Cognitive and emotional distress evaluation for undergraduate teachers. Social and Behavioural Sciences, 33, 203-207.

Mahfar, M. (2015). The analysis of validity and reliability of Malaysian teachers irrational beliefs for secondary school teachers. Unpublished Report of Potential Academic Staff (PAS), Research University Grant (RUG). Q.J.130000.2729.00K02. (2012-2013). 
Mahfar, M., Noah, S. M., Ahmad, J., \& Jaafar, W. M. W. (2012). The relationship between irrational beliefs system and stress among fully residential school students in Johor. Jurnal Teknologi, 59, 115-123.

Manshor, A. T., Fontaine, R., \& Choy, C. S. (2003). Occupational stress among managers: A Malaysian survey. Journal of Managerial Psychology, 18(6), 622-628.

McCarthy, C. J., Lambert, R. C., O’Donnell, M., \& Melendres, L. T. (2009). The relation of elementary teachers' experience, stress, and coping resources to burnout symptoms. Elementary School Journal, 109, 282-300. https://doi.org/10.1086/592308

Meehan, K. E. (2011). Examining the relationship between irrational beliefs, rational emotive coping strategies, and teachers burnout. New York: ProQuest.

Mogoaşe, C., Ştefan, S., \& David, D. (2013). How do we measure rational and irrational beliefs? the development of rational and irrational beliefs scale (RAIBS) - A new theory-driven measure. Journal of Cognitive and Behavioral Psychotherapies, 13(2a), 529-546.

Ohue, T., Moriyama, M., \& Nakaya, T. (2011). Examination of a cognitive model of stress, burnout, and intention to resign for Japanese nurses. Japan Journal of Nursing Science, 8(1), 76-86. https://doi.org/10.1111/j.1742-7924.2010.00161.x

Samad, N. I. A., Hashim, Z., Moin, S., \& Abdullah, H. (2010). Assessment of stress and its risk factors among primary school teachers in the Klang Valley, Malaysia. Canadian Center of Science and Education, 2(2), 163-171. https://doi.org/10.5539/gjhs.v2n2p163

Sekaran, U., \& Bougie, R. (2010). Research methods for business: A skill-building approach. Chichester: Wiley.

Shernoff, E. S., Mehta, T. G., Atkins, M. S., Torf, R., \& Spencer, J. (2011). A qualitative study of the sources and impact of stress among urban teachers. School Mental Health, 3, 59-69. https://doi.org/10.1007/s12310-011-9051-z

Stebbins, P., \& Pakenham, K. I. (2001). Irrational schematic beliefs and psychological distress in caregivers of people with traumatic brain injury. Rehabilitation Psychology, 46(2), 178-194. https://doi.org/10.1037/0090-5550.46.2.178

Tanhan, F. (2014). An analysis of factors affecting teachers' irrational beliefs. Educational Sciences: Theory \& Practice, 14(2), 465-470. https://doi.org/10.12738/estp.2014.2.1724

Tanhan, F., \& Şentürk, E. (2011). Development of teacher attitude scale towards undesirable intraclass behaviours of students. Journal of Turkish Psychological Counseling and Guidance, 4(35), 44-53.

Ugwoke, S. C., Eseadi, C., Onuigbo, L. N., Aye, E. N., Akaneme, I. N., Oboegbulem, A. I., \& Ezenwaji, I. O. (2018). A rational-emotive stress management intervention for reducing job burnout and dysfunctional distress among special education teachers: An effect study. Medicine, 97, 17(e0475). https://doi.org/10.1097/MD.0000000000010475

Walen, S. R., DiGiuseppe, R., \& Dryden, W. (1992). A practitioner's guide to rational-emotive therapy (2nd ed.). New York, NY: Oxford University Press.

\section{Copyrights}

Copyright for this article is retained by the author(s), with first publication rights granted to the journal.

This is an open-access article distributed under the terms and conditions of the Creative Commons Attribution license (http://creativecommons.org/licenses/by/4.0/). 